Intervening in the media's influence on stereotypes of race and ethnicity:

The role of media literacy education

\title{
Erica Scharrer
}

University of Massachusetts Amherst

Srividya Ramasubramanian

Texas A\&M University

\begin{abstract}
Author Note
Please address correspondence to Erica Scharrer, scharrer@comm.umass.edu, N312

Integrative Learning Center, Department of Communication, University of Massachusetts Amherst, 01003. Phone: 413-545-6339.
\end{abstract}




\begin{abstract}
The present paper provides a review of the research record on the potential for media literacy education to intervene in the media's influence on racial and ethnic stereotypes, and explores the theoretical concepts that underlie these efforts. It situates media literacy theory and practice within particular emphases in the field and synthesizes qualitative and quantitative studies. Quantitative research on the effect of media literacy training and mediated counterstereotypes on reducing racial/ethnic prejudice is described. Additionally, we report qualitative data from an ongoing study of early adolescents who took part in a media literacy curriculum on stereotypes. The research record reveals that although the topic is severely understudied, media literacy education holds great promise for its ability to shape media-related knowledge, attitudes, and behaviors and encourage an active and critical stance toward media.
\end{abstract}

Keywords: media literacy, media education, media stereotypes. 
Intervening in the media's influence on stereotypes of race and ethnicity:

The role of media literacy education

Media have been shown to have the potential to promote or to call into question stereotypical views of social groups, including those defined by race, ethnicity, gender, and sexual identity (Mastro, in press; Tukachinsky, Mastro \& Yarchi, in press). Accordingly, there is promise for education efforts addressing the media's role in stereotyping to mitigate the effects of exposure to negative or narrow media depictions of social groups and possibly even enhance the positive media influence of exposure to non-stereotypical and favorable media depictions. Can media consumers' examination of the principles and practices behind media production, media content, and media reception facilitate critical analysis of media's treatment of underrepresented social groups and open up their views of race and ethnicity? Might media literacy education help to increase knowledge and/or shape attitudes about media's roles and practices pertaining to race and ethnicity? The research concerning these critical questions is in its nascent stages. However, a number of studies on these and other related topics, as well as ongoing efforts by the authors of this paper, shed light on this socially significant issue. Prior to reviewing the relevant body of research, it is necessary, first, to situate the notion of media literacy as intervention within the broader field of media literacy education.

\section{Media Literacy: Theory and Definitions}

Media literacy has been defined as "the ability to access, analyze, evaluate and communicate messages in a variety of forms" (Aufderheide, 1993, p. xx), and the goal of encouraging critical thinking regarding media content and practices has been closely associated with media literacy education (Martens, 2010; Scharrer, 2007; Silverblatt, 2008). Yet, disagreements remain in conceptualizations of media literacy regarding issues such as the role of 
media production skills; whether critique should involve activism against mainstream commercial media; and whether the purpose of media education should include protecting young people from negative influence or whether such as purpose is too dogmatic or misguided (Hobbs, 1998). Some scholars (Buckingham, 1998; Kubey, 1998) have drawn a distinction between two different approaches -- one favoring the role of pleasure and creative expression; assuming an active audience (focusing on what youth do with media) and the other approach, considering media literacy education as a potential intervention in media influence (focusing on what media do to youth and what can be done about that). In the latter category, when one considers media literacy education as an "intervention," the necessary underlying assumption is that there is a relationship between media use and some (undesirable) outcome that needs to be addressed. At the same time, the observation that many media literacy curricula blur and blend these approaches has also been voiced in the field (Scharrer, 2007). In our review and synthesis of the literature, we bring together qualitative approaches (often more aligned with the "what youth do with media" approach) and quantitative approaches (often aligned with the "what media do to youth, and what can be done about it" approach) in an attempt to fully explore the available data on the topic. Studies on the topic of racial and ethnic stereotypes employ various methods that range from interviews, focus groups and in-depth analysis of student work to surveys and experiments. However, media literacy education has largely been conducted toward the shared goal of critiquing narrow media practices and representations, acknowledging and envisioning broader and more balanced practices and representations, and working toward a more just range of portrayals.

There are a number of pertinent theoretical underpinnings of media literacy as intervention, including inoculation theory (McGuire, 1964) which suggests prior exposure to a 
persuasive attempt (particularly when encountered through a critical lens) can help reduce the impact of subsequent persuasive attempts. However, we caution that the use of the term "inoculation" brings to mind a powerful effects model of media influence that is likely to be an oversimplification; connoting a uniform and unavoidable response occurring as if through a "hypodermic needle" or expressed as resistance to influence via media literacy education.-

Potter (2004) has advanced a cognitive information processing framework, which posits that media literacy is facilitated through increases in media knowledge (about media content, effects, industries, etc.), which together with the individual's information processing efforts, help stimulate competencies such as the critical analysis of media. Media literacy, in turn, can produce immediate outcomes such as critical viewing skills, heightened awareness of media influence, and decreases in perceived realism of media texts. Finally, Austin's message interpretation process (MIP) model (Austin \& Meili,1994) suggests individuals process media messages and internalize or reject them based on comparisons of the media message to an individual's sense of generalized others as well as to the individual's personal experience. The model introduces affective and cognitive processing routes and presents a number of variables that predict which route the individual will employ in making sense of the media message.

Quantitative studies of media literacy educational efforts regarding such topics as violence (Rosenkoetter, Rosenkoetter, Ozretich, \& Acock, 2004; Scharrer, 2005, 2006), body image (Tiggemann, Gardner, \& Slater, 2000; Wilksch, Tiggemann, \& Wade, 2006), advertising (Livingstone \& Helsper, 2006; Rozendaal, Lapierre, van Reijmersdal, \& Buijzen, 2011), and alcohol and tobacco use (Austin \& Meili, 1994; Banerjee \& Greene, 2007) indicate media literacy interventions can, indeed, shift attitudes and promote knowledge. Yet, some of these studies suggest that completely disrupting media influence (such as media literacy preventing 
young people from experiencing susceptibility to advertisements, e.g., Rozendaal et al., 2011 or

to images of a thin ideal, e.g., Tiggemann et al., 2000) can be more difficult to achieve.

Jeong, Ho, and Hwang (2012) conducted a meta-analysis of 51 quantitative studies of the influence of a "structured media literacy intervention" (p. 459). The overall effect size was moderate $(d=.37)$, indicating a positive role of media literacy interventions in shaping multiple outcomes. The effects were most substantial for knowledge $(d=1.12)$, followed by effects on consumers' belief that media exert an influence $(d=.60)$, realism $(d=.54)$, criticism (e.g., skepticism, understanding of persuasive intent, $d=.29)$, attitudes $(d=.28)$, and behaviors $(d=$ .23). Media literacy interventions with longer or more sessions resulted in larger effect sizes whereas interventions with more components (such as critical analysis of media clips in addition to student activities as well as hands-on media production assignments) were associated, perhaps counterintuitively, with smaller effect sizes. Age did not have a role in shaping effect size, although participants varied from children to college students. For the current focus, it should be noted that only one of the 51 studies in the meta- analysis dealt directly with our topic of racial and ethnic stereotyping (i.e., Ramasubramanian \& Oliver, 2007) and the pattern in which behavioral effects appear to be more resistant to change compared to effects on knowledge and beliefs about media should be noted, as well.

\section{Effectiveness of Media Literacy Interventions in Reducing Racial and Ethnic Stereotypes}

Despite these theoretical explanations and continuing development in other topic areas, there are currently very few studies of the role of media literacy education in reducing stereotypes. The majority of the existing research on the topic employs qualitative methods to closely examine young people's responses to curricula that include the critical analysis of media depictions of racial and ethnic stereotypes. An even smaller number of quantitative studies are 
available on the topic. These are most closely associated with the media literacy as intervention conceptualization and typically take an experimental approach to study the effects of media literacy training and counter-stereotypes on reducing racial/ethnic prejudice.

\section{Quantitative Approaches}

Very few experimental studies examine the role of media-based interventions on racial/prejudice reduction (Cole et al., 2003; Gorn, Goldberg \& Kanungo, 1976; Paluck, 2009; Ramasubramanian, 2007, 2011). Most of these studies have examined the role of children's educational television programs. For example, Gorn and colleagues (1976) randomly assigned Canadian nursery school children to either the experimental condition where they watched multiracial themes inserts from Sesame Street or to the control condition. White children in the experimental condition reported a greater willingness to want to play with non-White children than those in the control condition. Similarly, exposure to positive intergroup messages in Sesame Street also reduced intergroup stereotypes amongst Israeli and Palestinian children (Cole et al., 2003). Media-based interventions aimed at reducing intergroup conflict and increasing harmony with adult populations are fewer still. Paluck (2009) conducted a field experiment in Rwanda where participants were assigned to listen to either an experimental 20-minute radio clip about prejudice, violence, and trauma or to a control clip from a soap opera about AIDS. Yet, the two groups did not show any statistically significant differences in terms of beliefs about bystander responsibility, interracial marriage, and trauma related to conflicts.

Given the quasi-experimental nature of prior quantitative research studies on media literacy interventions, it is very difficult to understand the processes by which media literacy educational materials lead to prejudice reduction. Even if there is a control group within a study, the participants in this condition do not undergo any type of training at all, making it difficult to 
control for confounding variables. Most of the literacy training materials themselves contain many examples of stereotypes, which make it unclear if the instructional content itself acts as a prime in activating stereotypes. Another drawback is that most studies have been conducted with school-age children although media literacy is a lifelong skill and practice.

Ramasubramanian (2007) conducted a lab-based experiment that compared WhiteAmerican audiences' implicit racial prejudice in response to a 12-minute media literacy training or control video, after which they read stereotypical or counter-stereotypic news stories featuring African Americans and Asian Indians. The findings suggest that implicit racial prejudice was most effectively reduced when a combination of audience-centered and message-centered approaches were used. Audience-centered strategies take a more motivational approach by developing media literacy and critical viewing and thinking skills amongst audiences, with an example being a scenario in which an expert (such as a media literacy facilitator) explicitly encourages a negative view of stereotyping by appealing to audiences' cognitive processing. In contrast, message-centered strategies such as exposure to counter-stereotypes (e.g., a media example featuring a depiction that runs directly counter to a common stereotype used as an experimental stimulus) may offer a more proactive alternative to achieve similar goals, which are easier to manipulate and require lesser mental efforts than motivational strategies.

Social psychological research on motivational approaches to prejudice reduction informs us that negation training, emphasis on self-enhancement goals, and motivation to appear nonprejudiced can curb or change even implicit prejudice (Blair, 2002; Stewart \& Payne, 2008). However, the main concern with these strategies is that they require substantial cognitive resources and concerted efforts on the part of the perceiver. There is also a possibility that stereotype suppression can sometimes lead to ironic boomerang effects. For example, avoidance 
strategies lead to unintended stereotyping (Macrae, Milne, \& Bodenhausen, 1994; Monteith, Sherman, \& Devine, 1998). Similarly, Ramasubramanian and Oliver (2007) found boomerang effects such that those in the media literacy condition were more likely than those in the control group to report higher stereotypes.

Prior research has shown that exposure to counter-stereotypic exemplars in the media can have a positive effect on intergroup relations (Bodenhausen, Schwarz, Bless, \& Waenke, 1995; Dasgupta \& Greenwald, 2001; Mastro \& Tukachinsky, 2011; Power, Murphy, \& Coover, 1996; Ramasubramanian, 2007; 2011; in press; Ramasubramanian \& Oliver, 2007). For instance, Power and colleagues use media priming to show that participants are less prejudiced in their interpretations of news stories in a subsequent task. Similarly, Bodenhausen and colleagues (1995) use the generalized appraisal model to show that when White audiences are not made conscious of the atypicality of successful and likable African-American media celebrities, they are more likely to have positive attitudes towards this racial/ethnic out-group in general.

Dasgupta and Greenwald (2001) varied the likeability and the race of exemplars (e.g., Denzel Washington compared to Mike Tyson, Tom Hanks compared to Jeffrey Dahmer) and used the Implicit Association Test to determine whether accessibility of the exemplar affected individuals' automatic racial attitudes. Results showed that exposure to the Black, liked individual and the White, disliked individual led to lower scores on pro-White attitudes among participants. Ramasubramanian (2011) conducted an experiment using an exemplar-based model of policy reasoning. The study suggests that exposure to counter-stereotypical media exemplars (i.e., positive versus negative African-American celebrities) decreases internal causal attributions for failures of African-Americans and increases support for affirmative action. Similarly, experimental findings (Ramasubramanian, in press) show that exposure to counter-stereotypes as 
compared to stereotypic exemplars in news stories about African-Americans are associated with lower subtle symbolic prejudice and increased support for affirmative action policies.

Overall, the quantitative research on media literacy interventions suggests that they are likely to be most effective when used in conjunction with message-centered approaches such as exposure to counter-stereotypic media exemplars. These media-based approaches to prejudice reduction serve as an effective, viable, and proactive strategy to motivational techniques such as negation training. Mediated contact with positive out-group media characters is a less anxietyprovoking and more practical approach to prejudice reduction compared to traditional intergroup face-to-face positive contact (Bodenhausen et al, 1995; Schiappa, Greg, \& Hewes, 2005).

\section{Qualitative Approaches}

Qualitative approaches to the topic of media literacy education regarding race and ethnicity typically employ open-ended data gathering techniques and foreground the complex relationships between media consumers and media texts. Hobbs, Cabral, Ebrahimi, Yoon, and Al-Humaidan (2010) gathered qualitative evidence from interviews and student work to investigate the potential for media literacy lessons to reduce stereotyping of the Middle East among $3^{\text {rd }}$ and $4^{\text {th }}$ graders. Students who had participated in the lessons were able to articulate the notion that popular media helped to form their impressions of the Middle East, and they used their own research about the region to identify stereotypes and inaccuracies within visual images supplied by the researchers and within a 13-minute clip from the film, Aladdin.

Vargas (2006) worked with a group of transnational Latina teenagers - foreign-born or first-generation female U.S. adolescents - in a program focused on resistance of the stereotypical, often pejorative, media portrayals of Hispanic and Latina individuals. Using ethnographic, in-depth interview method, Vargas observed that, towards the completion of the 
program, the participating teenagers showed recognition of the underrepresentation and stereotypical depictions of Latinos/as in media and examined the distance between their own perceptions of self and the mainstream depictions they critiqued.

Yosso (2002) shares findings from a critical media literacy curriculum in which Latino/a community college students in California examined clips from films depicting Latinos/as stereotypically -- as unsuccessful students, unengaged parents, and as violent or hyper-sexual. Qualitative analysis demonstrated that students responded to the curriculum in one of three ways: confrontation — challenging the stereotypes they saw in the media clips; motivation — sparking the desire to prove the stereotypes wrong; and navigation-articulating specific plans to enact roles directly opposed to the stereotypes they encountered. Brooks and Ward (2007) used discourse analysis to study college students' responses to a course on race, gender, and media, and found students' responses to films and class discussion remained largely connected with a colorblind ideology in which race is considered unimportant and white privilege is unquestioned.

Dunlop (2007) put into place a two-week long media literacy curriculum among high school students in a predominantly White suburban context in the Midwest and used grounded theory to organize interview data regarding students' views on media representations of race. Some such data indicated students had understood a link between systemic social issues and racial stereotypes in the media, whereas others showed defensive or deflective views, including those that reinforced in groups and out groups ("Us vs. Them") and those that suggested the issue was germane only to "other people."

Through a college-level media literacy course entitled "Thinking Television Project" (TTP), Kavoori (2007) aimed to engage college students in challenging stereotypical media depictions of African Americans through media reading and production activities. Students 
demonstrated awareness and critical thinking about the role of media in perpetuating racial stereotypes about African Americans, and were also shown to be conscious about the influence of the commercial media landscape on the images that are advanced in media. Nevertheless, when it came to their own media productions, they still relied on stereotypical racial portrayals of African Americans in the constructing the plots and characters, and used the assumption that audiences would read their productions as satire as a means of defending their decisions.

There are a number of conclusions to draw from this body of existing qualitative research investigations of young people's reception of media literacy education regarding race and ethnicity in the media. First, there is some evidence (among even the very young) that media education can promote an understanding of the role of media in producing and reproducing stereotypes related to such social groups as Arabs (Hobbs et al., 2010), Latinos (Vargas, 2006; Yosso, 2002) and Blacks or African Americans (Kavoori, 2007). Importantly, some of these studies examine such knowledge and critical awareness among members of non-dominant groups themselves. Doing so, extends research conclusions regarding media consumers' selfperceptions, in ways that challenge and defy the narrow mainstream depictions (Vargas, 2006; Yosso, 2002). There is some evidence that media literacy education can promote an understanding of the systemic and structural conditions that shape racial conditions in society (Dunlop, 2007). At the same time, there are also indications that media literacy can inadvertently reinforce distinctions perceived between in groups and out groups (Dunlop, 2007) or promote the misplaced notion of a colorblind ideology that assumes racism is a condition of the past (Brooks $\&$ Ward, 2007). Indeed, Kavoori's (2007) finding that college students were able to critique African American stereotypes in the media and understand that commercial forces allow for such depictions, yet still reproduce stereotypes when asked to create their own media messages 
demonstrates just how embedded prejudicial views can be.

\section{New Qualitative Media Literacy Data on Media and Stereotypes}

Another original, and currently ongoing, research project conducted by the first author and her colleagues employed a media literacy lesson plan that focused on depictions of violence in the media, economic explanations for the presence of media violence, and the presence or absence of gender, class, race, and ethnicity stereotypes in media content. Sixty sixth-graders from a rural, predominantly White location in New England participated in the project (46\% female). Participants provided data in the form of written responses to homework questions. An inductive approach was utilized to explore the degree to which students' writing reflects critical thinking about stereotypes and violence in media. To this end, the analysis identified themes in students' homework responses that represent the ways in which they made sense of the lessons, The study draws from prior analyses of the themes present in early adolescents' qualitative responses to a media literacy curriculum on violence and gender stereotypes (Scharrer \& Wortman Raring, 2012; Walsh, Sekarasih, \& Scharrer, 2014).

One class of participating sixth-grade students $(n=17)$ was shown clips to critique that pertained to media with which they were presumably familiar-recent and current television programs, movies and video games that a prior informal survey showed they watched or played regularly. Another class of participating sixth-grade students $(n=13)$ were shown older clips that may that they may not already have been familiar with or been fans of, to attempt to ascertain whether degree of relevance or attachment to a media example might shape the capacity to critique it. One clip pertaining to ethnic stereotyping was from the highly popular sitcom, Modern Family, and featured Sophia Vergara's Gloria character on an emotional, loud rant in which she mixes Spanish and English words and uses an angry tone played for laughs for its 
incomprehensibility. A clip showing racial stereotyping was from the reality television program, Dance Moms. In the clip, Abby (the dance coach) made Nia, an African American girl, dance what Abby called an "ethnic dance" entitled "They Call Me Laquifa." Nia was the only nonwhite contestant in the reality show, and was the only dancer that was asked to do "ethnic dance" and the clip included a depiction of Nia's mother's experience of taking offense.

Other clips used in the media literacy lessons pertained to gender stereotypes and included a clip portraying masculine gender roles on Duck Dynasty and a clip in which a female character (Kristen Stewart's Bella) is rescued by a male character in the film, Twilight. Finally, students were shown a clip from the reality television program Here Comes Honey Boo Boo and were prompted to consider social-class based stereotypes, as well. Data pertaining to the gender and class-based stereotypes were considered outside the present scope of and therefore will not be included in great detail here. In their writing assignment, students were given the option of choosing one of these clips and responding in writing to the questions: How would you feel if you were portrayed in these limited ways? What messages are producers trying to get across through these depictions?

What is most striking across the group of sixth-grade students who were presented with the presumably relevant and familiar media clips was their overwhelming tendency to choose to discuss the clips having to do with gender stereotypes rather than racial or ethnic ones. Among the 4 students who did address race or ethnicity, one student, Caleb (a pseudonym, as are the other mentions of participating students' names), responded to the Modern Family clip, noting "no one could understand what she said." Susan brought up the same clip and reported that she would feel "Racial discrimination, and if I am doing this (speaking in the way the character had), I would be called stupid." Finally, Anna wrote "If I were born in Colombia like Gloria from 
Modern Family I wouldn't want to be portrayed as loud and can't speak very well." Just one student, Karen, discussed the Dance Moms clip and noted, "In Dance Moms, I would probably feel bad because just because she was a different color/African American doesn't mean she can't choose what she wants to wear and stuff and pick a song and her theme."

Among the 13 sixth-grade students who critiqued the less familiar media content, none chose to focus on racial or ethnic stereotypes in their written work despite the lesson plan for their class including critique of clips from the films the Karate Kid (for Asian stereotypes) and Lawrence of Arabia (for Arab stereotypes). Instead, they responded to a clip from the television show Smallville in which the Lois Lane character is rescued by the Superman character and to a weight loss clip targeted toward women.

Follow-up questions asked students to consider the positive role of media in depicting individuals and social groups as well as the negative potential of such depictions. In this case, the distinction between whether the sixth graders saw more or less recent media examples appeared to not matter at all, and the constant comparison method was used to generate themes across the two groups. Among the themes emerging regarding the negative consequences of media stereotypes, many students wrote about potential effects on audiences. Ben, for instance, suggested "People will try to live up to stereotypes" and Daniel expressed concern about "when people think they have to be like the people in the ads." Megan wrote, "Media can display people in a negative way because of their race and gender and make you feel that way too." Zachary had this to say about media: "The media is pretty much a big example of stereotypes and making people not feel good enough. It can make people feel left out..."

Another emergent theme was around emphasizing differences among people rather than similarities. Karen, for instance, expressed the following: "Sometimes it's not okay for 
them to single people out because of there (sic) race or religion or anything different about them." Finally, a third theme within responses regarding the negative role of media in depicting social groups was that stereotypes send messages that are limiting and inaccurate. Emily suggested, for example, "They can be dangerous because it makes people assume things and prejudge others without getting to know them. Although, some people aren't like the stereotypes, so they are thought to be who they aren't." Jackson suggested that media "gives us limited information about people, places, and things." Anna combined the first theme about concern about effects and the third regarding the limits of stereotypes in her response, suggesting media stereotypes are important "Because it can make people feel they have to act a certain way...That you should fit in with a certain category."

Within those responses having to do with positive effects of media depictions of racial and ethnic groups, the prevailing emerging theme was exposure to diverse experiences and points of view. Ben, for instance, wrote "It shows us different experiences from different people" and Emily pointed out the media "can help us understand other people because they try to tell us what other people like to do. So we know how other people live and what they usually do." Aaron suggested, as a positive, "It can help us by showing someone's view and maybe that can relate to other people's views." Somewhat similarly, Jennifer pointed out the positive possibilities of "Showing you people's point of view. Knowing different experiences. Understanding them as a person." Jackson noted the favorable possibility that media "can help us to understand others, other places" and Megan suggested that "Media can help us understand people's point of view by displaying experiences and reactions in a different way."

There are a number of tentative conclusions to draw from this small sample of predominantly White early adolescents and their responses to media literacy lesson plans 
focusing on media and stereotypes. First, it is overwhelmingly apparent that when given the choice to write about any of the media clips examined, the sample of sixth graders in these data generally chose to take up gender stereotypes rather than racial and ethnic or social class related stereotypes. This could be interpreted in view of their own race (again, most were White, although a small number were Asian) and ethnicity (most were non-Latino) and may suggest they related more to the gender portrayals they had seen and critiqued as a class. Yet, it also may be an indication of discomfort in speaking about race, or even a greater acceptance of race- and ethnicity-based stereotypes. Finally, the choice of particular media examples/clips used to broach the topic may have also shaped responses. Even in the class in which recent/preferred media content was used as media examples, perhaps the small number of students who chose to discuss the racial and ethnic stereotypes did so because they found the Modern Family and Dance Moms examples to be unappealing; a condition that was perhaps also created, in the class in which older/less preferred content was used (again, with Karate Kid and Lawrence of Arabia as options not taken up at all by students). This is certainly a limitation of the current approach, as is the small sample of primarily White students from a relatively privileged economic background and the short duration of the media literacy unit on race and ethnicity in media.

Nonetheless, if we consider the quotes from the writing assignments among those in the first class that did, indeed, engage with the racial and ethnic media stereotypes, a range of responses to the exercise are apparent. The three sixth graders who responded to the Modern Family Latina stereotype clip, for example, ranged from a purely descriptive reaction (Caleb's noting that it was hard to understand the Gloria character) to a personal response (Anna's confession that she wouldn't want to be depicted in that way) to a more evaluative outcome (Susan's use of the label "racial discrimination" to describe the clip). For the one student who 
wrote about the Dance Moms depiction of the stereotyping of an African American character, it is difficult to know whether Karen understood the degree of offensiveness of the actions of the dance coach, as her response mostly focused on the lack of choice the coach imposed on Nia rather than the stereotypical assumptions underlying the coach's choice for Nia.

Finally, in the data from all 30 sixth grade students in their written responses to the question asking them to consider both positive and negative potential in media's representations of social groups, the prevailing theme regarding the positive role of media in representing social groups was that such representations can be used to understand multiple points of view and experiences. The main themes regarding the negatives were that media representations tend toward the restrictive and therefore may impose effects on audience members. Students variously described such effects on non-dominant racial and ethnic group members themselves (e.g., people may feel "inferior" or "bad" or may even act in a way that fits the stereotype) as well as on dominant groups' views of out groups (e.g., Emily's reference to "pre-judging” others on the basis of media stereotypes). Clearly, these young students were grappling with the ways in which media could potentially constrict and constrain views of self and others according to race and ethnicity or, conversely, open them up to additional information, complexity, and understanding by providing depictions that extend beyond one's own first-hand experiences. When considering responses across both the positive and negative consequences, we see this group of early adolescents is able to reason through the potentially contradictory ways in which media can shape views of self and other, for better or for worse.

\section{Conclusions}

Many of the critical questions in the opening paragraphs of this paper remain unanswered by the social science research record to date, including perhaps the most important question of 
all: Can media literacy education reduce the media's role in perpetuating stereotypes? We have precious little data to apply to that socially significant question. It is our hope that this article will inspire researchers to take up this important topic in future research.

Although limited in size and scope, the existing quantitative research can be used to draw some preliminary observations. In other topic areas, for instance, we have seen evidence of successful outcomes associated with media literacy education, particularly when curricula are focused and cohesive as well as when they employ multiple and longer sessions (Jeong et al., 2012). Future media literacy efforts addressing racial/ethnic stereotypes and targeting outcomes such as criticism, considerations of realism, fostering of knowledge, and shifting of both attitudes and behaviors (all measured in the Jeong et al.'s, 2012 meta-analysis) would do well, then, to attend to these characteristics. The work of Ramasubramanian also points to the importance of employing auspicious media exemplars that provide White non-Latino audiences with a positive intergroup experience (albeit a mediated rather than face-to-face one) (Ramasubramanian, 2007, 2011, 2014; Ramasubramanian \& Oliver, 2007).

Positive depictions and the potential for the media to play a progressive role in intergroup dynamics in society are also an important component of the qualitative research. In the data presented in this chapter, for instance, the early adolescent participants (most of whom were 12 years old) were readily able to articulate the possibility that media depictions that defy stereotypes could function positively in society by promoting multicultural understanding and diverse points of view. The media literacy participants of color in the Vargas (2006) and Yosso (2002) studies were motivated to demonstrate how their own actions and identities ran counter to the narrow depictions of mainstream media that they critiqued.

At the same time, of course, many depictions of people of color in commercial media do 
embody stereotypes, and students can be inspired to critique those depictions and the institutional forces that create them in another potentially fruitful component of media literacy education. The current data and the other research reviewed in this chapter, although limited in size and nature, suggest adolescents as young as age 12 readily recognize the limits of popular media's treatment of race and ethnicity and the harm that can come of such treatment to members of racial and ethnic "minorities" as well as to White individuals" perceptions of and interactions with these groups. Such findings have important implications for the social issue of ethnic and racial stereotyping, suggesting that media literacy efforts with young people can, indeed, help address prejudice and racial bias and promote an appreciation for diversity and multiculturalism. By acknowledging media and popular culture as an important socializing agent to interpret, analyze, and critique for its role in creating, maintaining, and disrupting stereotypes, such efforts can operate alongside more traditional subjects within the educational curriculum to direct young people toward more nuanced understandings of identity and social groups. Based on our research and others', we suggest future research efforts should specifically carefully consider the complementary analysis of media stereotypes as well as media counter-stereotypes in a media literacy educational framework, utilize contemporary examples from media content with which young people can presumably relate, actively involve young people in the curriculum rather than employing a "top-down" or overly dogmatic approach, and probe racial and ethnic stereotypes as an important component of stereotyping and the media in their own right, lest students limit their analysis to other social group formations presumably "easier" to critique, such as gender. With media use occupying increasing amounts of young people's daily experience, future social science research is needed to fully understand the role of media literacy in intervening in the formation of racial and ethnic stereotypes. 


\section{References}

Aufderheide, P. (1993). National leadership conference on media literacy. Conference report. Washington, DC: Aspen Institute.

Austin, E.W., \& Meili, H.K. (1994). Effects of interpretations of televised alcohol portrayals on children's alcohol beliefs. Journal of Broadcasting \& Electronic Media, 38, 417-435. Doi: 10.1080/08838159409364276.

Banerjee, S. C., \& Greene, K. (2007). Antismoking initiatives: Effects of analysis versus production media literacy interventions on smoking-related attitude, norm, and behavior intention. Health Communication, 22(1), 37-48. Doi: 10.1080/10410230701310281.

Blair, I. V. (2002). The malleability of automatic stereotypes and prejudice. Personality and Social Psychology Review, 6(3), 242-261. Doi: 10.1207/S15327957PSPR0603_8.

Bodenhausen, G. V., Schwarz, N., Bless, H., \& Waenke, M. (1995). Effects of atypical exemplars on racial beliefs: Enlightened racism or generalized appraisals? Journal of Experimental Social Psychology, 31, 48-63. Doi: 10.1006/jesp.1995.1003.

Brooks, D.E., \& Ward, C.J. (2007). Assessing students' engagement with pedagogies of diversity. Journalism \& Mass Communication Educator, 62, 244-262. Doi: 107769580706200303.

Buckingham, D. (1998). Media education in the UK: Moving beyond protectionism. Journal of Communication, 48(1), 33-43. Doi: 10.1093/joc/48.1.33.

Cole, C., Arafat, C., Tidhar, C., Tafesh, W. Z., Fox, N., Killen, M., \& Richman, B. (2003). The educational impact of Rechov Sumsum/Shara'a simsim: A Sesame Street television series to promote respect and understanding among children living in Israel, the West Bank, and 
Gaza. International Journal of Behavioral Development, 27(5), 409-422. Doi:

10.1080/01650250344000019.

Dasgupta, N., \& Greenwald, A. G. (2001). On the malleability of automatic attitudes: Combating automatic prejudice with images of admired and disliked individuals. Journal of Personality and Social Psychology, 81, 800-814. Doi: 10.1037//0022-3514.81.5.800.

Dunlop, J.C. (2007). Effects of media literacy instruction: Recognizing and analyzing racial stereotypes in media. Unpublished doctoral dissertation. Oklahoma State University.

Gorn, G. J., Goldberg, M. E., \& Kanungo, R. N. (1976). The role of educational television in changing the intergroup attitudes of children. Child Development, 47(1), 277-280. Doi: $10.2307 / 1128313$

Hobbs, R. (1998). The seven great debates in the media literacy movement. Journal of Communication, 48, 16-32. Doi: 10.1093/joc/48.1.16.

Hobbs, R., Cabral, N., Ebrahimi, A., Yoon, J., Al-Humaidan, R. (2010).Combating Middle East stereotypes through media literacy education in elementary school. Paper presented at the annual meeting of the International Communication Association.

Jeong, S.H., Cho, H., \& Huang, Y. (2012). Media literacy interventions: A meta analytic review. Journal of Communication, 62, 454-472. Doi: 10.1111/j.1460-2466.2012.01643.x

Kavoori, A. (2007). Media literacy, “Thinking Television,” and African American communication. Cultural studies/ Critical Methodologies, 7(4), 460-483. Doi: $10.1177 / 1532708607305038$.

Kubey, R. (1998). Obstacles to the development of media education in the US. Journal of Communication, 48, 58-69. Doi: 10.1093/joc/48.1.58.

Livingstone, S., \& Helsper, E. J. (2006). Does advertising literacy mediate the effects of 
advertising on children? A critical examination of two linked research literatures in relation to obesity and food choice. Journal of Communication, 56(3), 560-584. Doi: 10.1111/j.1460-2466.2006.00301.x.

Macrae, C. N., Milne, A. B., \& Bodenhausen, G. V. (1994). Stereotypes as energy-saving devices: A peek inside the cognitive toolbox. Journal of Personality and Social Psychology, 66(1), 37. Doi: 10.1037//0022-3514.66.1.37.

Martens, H. (2010). Evaluating media literacy education: Concepts, theories and future directions. Journal of Media Literacy Education, 2(1), 1-22.

Mastro, D. (in press). Why the media's role in issues of race and ethnicity should be in the spotlight. Journal of Social Issues, $x, \mathrm{xx}-\mathrm{xx}$

Mastro, D., \& Tukachinsky, R. H. (2011). Exemplar versus prototype-based processing of media content and the influence on racial/ethnic evaluations. Journal of Communication, 61, 916-937. Doi: 10.1111/j.1460-2466.2011.01587.x.

McGuire, W. J. (1964). Inducing resistance to persuasion: Some contemporary approaches. In L. Berkowitz (Ed.), Advances in experimental social psychology, Vol. 1 (pp. 192-229), New York, NY: Academic Press. Doi: 10.1037/h0044167.

Monteith, M. J., Sherman, J. W., \& Devine, P. G. (1998). Suppression as a stereotype control strategy. Personality and Social Psychology Review, 2(1), 63-82. Doi: 10.1207/s15327957pspr0201_4.

Paluck, E. L. (2009). Reducing intergroup prejudice and conflict using the media: A field experiment in Rwanda. Journal of Personality and Social Psychology, 96(3), 574-587. Doi: $10.1037 / \mathrm{a} 0011989$.

Potter, W.J. (2004). Media literacy. Thousand Oaks, CA: Sage. 
Power, J. G., Murphy, S. T., \& Coover, G. (1996). Priming prejudice how stereotypes and Counter-stereotypes influence attribution of responsibility and credibility among ingroups and outgroups. Human Communication Research, 23(1), 36-58. Doi: 10.1111/j.14682958.1996.tb00386.x.

Ramasubramanian, S. (2007). Media-based strategies to reduce racial stereotypes activated by news stories. Journalism \& Mass Communication Quarterly, 84(2), 249. Doi: 10.1177/107769900708400204.

Ramasubramanian, S. (2011). The impact of stereotypical versus counterstereotypical media exemplars on racial attitudes, causal attributions, and support for affirmative action. Communication Research, 38 (4), 497-516. Do: 10.1177/0093650210384854.

Ramasubramanian, S. (in press). Using celebrity news to effectively reduce racial./ethnic prejudice. Journal of Social Issues, $x$, xx-xxx.

Ramasubramanian, S., \& Oliver, M. B. (2007). Activating and suppressing hostile and benevolent racism: Evidence for comparative media stereotyping. Media Psychology, 9(3), 623. Doi: 10.1080/15213260701283244.

Rosenkoetter, L. I., Rosenkoetter, S. E., Ozretich, R. A., \& Acock, A. C. (2004). Mitigating the harmful effects of violent television. Journal of Applied Developmental Psychology, 25(1), 25-47. Doi: 10.1016/j.appdev.2003.11.005.

Rozendaal, E., Lapierre, M. A., van Reijmersdal, E. A., \& Buijzen, M. (2011). Reconsidering advertising literacy as a defense against advertising effects. Media Psychology, 14(4), 333-354. Doi: 10.1080/15213269.2011.620540.

Scharrer, E. (2005). Sixth graders take on television: Media literacy and critical attitudes about television violence. Communication Research Reports, 24, 325-333. Doi: 
$10.1080 / 00036810500317714$.

Scharrer, E. (2006). "I noticed more violence:" The effects of a media literacy program on critical attitudes toward media violence. Journal of Mass Media Ethics, 21(1), 69-86. Doi: 10.1207/s15327728jmme2101_5.

Scharrer, E. (2007). Closer than you think: Bridging the gap between media effects and cultural studies in media education theory and practice. In A. Nowak, S. Abel, \& K. Ross (Eds.), Rethinking media education: Critical pedagogy and identity politics (pp. 17-35). Cresskill, NJ: Hampton Press.

Scharrer, E., \& Wortman Raring, L. (2012). A media literacy curriculum on violence in the US: Studying young people's written responses for evidence of learning. Journal of Children \& Media, 6(3), 351-366. Doi: 10.1080/17482798.2012.693050.

Schiappa, E., Gregg, P. B., \& Hewes, D. E. (2005). The parasocial contact hypothesis. Communication Monographs, 72(1), 92-115. Doi: 10.1080/0363775052000342544.

Silverblatt, A. (2008). Media literacy: Keys to interpreting media messages. $3^{\text {rd }}$ edition. Westport, CT: Praeger.

Stewart, B. D., \& Payne, B. K. (2008). Bringing automatic stereotyping under control: Implementation intentions as efficient means of thought control. Personality and Social Psychology Bulletin, 34(10), 1332-1345. Doi: 10.1177/0146167208321269.

Tiggemann, M., Gardiner, M., \& Slater, A. (2000). "I would rather be size 10 than have straight A's": A focus group study of adolescent girls' wish to be thinner. Journal of Adolescence, 23(6), 645-659. Doi: 10.1006/jado.2000.0350.

Tukachinsky, R., Mastro, D., \& Yarchi, M. (in press). Documenting portrayals of race/ethnicity on television over a 20 year span and their association with national-level racial/ethnic 
attitudes. Journal of Social Issues, Volume number, xx-Xx.

Vargas, L. (2006). Translational media literacy: Analytic reflections on a program with Latina teens. Hispanic Journal of Behavioral Sciences, 28(2), 267-285. Doi:

$10.1177 / 0739986305285823$.

Walsh, K.R., Sekarasih, L., \& Scharrer, E. (2014). Mean girls and tough boys: Children's meaning making and media literacy lessons on gender and bullying in the US. Journal of Children \& Media, 8, 223-239. doi: 10.1080/17482798.2013.851094

Wilksch, S. M., Tiggemann, M., \& Wade, T. D. (2006). Impact of interactive school-based media literacy lessons for reducing internalization of media ideals in young adolescent girls and boys. International Journal of Eating Disorders, 39(5), 385-393. Doi:

10.1002/eat.20237

Yosso, T. (2002). Critical race media literacy: Challenging deficit discourse about Chicanas/os. Journal of Popular Film \& Television, 30, 52-62. Doi: 10.1080/01956050209605559. 


\begin{abstract}
Author Bios
Erica Scharrer (Ph.D., Syracuse University, 1998) is Professor and Chair in the Department of Communication at the University of Massachusetts Amherst. She studies media content, opinions of media, media effects, and media literacy, particularly regarding gender and violence.
\end{abstract}

Srividya Ramasubramanian (Ph.D., Penn State University) is Associate Professor in the Department of Communication at Texas A\&M University. She studies media effects and media stereotyping processes, especially in the context of race/ethnicity and gender. Her work looks at the media as a positive tool for prejudice reduction and media literacy. 